The importance of canopy complexity in shaping seasonal spider and beetle assemblages in saltmarsh habitats

Ford, Hilary; Evans, Ben; van Klink, Roel; Skov, Martin; Garbutt, Angus

\title{
Ecological Entomology
}

DOI:

10.1111/een.12373

Published: 01/04/2017

Peer reviewed version

Cyswllt i'r cyhoeddiad / Link to publication

Dyfyniad o'r fersiwn a gyhoeddwyd / Citation for published version (APA):

Ford, H., Evans, B., van Klink, R., Skov, M., \& Garbutt, A. (2017). The importance of canopy complexity in shaping seasonal spider and beetle assemblages in saltmarsh habitats. Ecological Entomology, 42(2), 145-155. https://doi.org/10.1111/een.12373

\section{Hawliau Cyffredinol / General rights}

Copyright and moral rights for the publications made accessible in the public portal are retained by the authors and/or other copyright owners and it is a condition of accessing publications that users recognise and abide by the legal requirements associated with these rights.

- Users may download and print one copy of any publication from the public portal for the purpose of private study or research.

- You may not further distribute the material or use it for any profit-making activity or commercial gain

- You may freely distribute the URL identifying the publication in the public portal ?

Take down policy

If you believe that this document breaches copyright please contact us providing details, and we will remove access to the work immediately and investigate your claim. 
1 The importance of canopy complexity in shaping seasonal spider and beetle assemblages

\section{2 in saltmarsh habitats}

3

4

5

6

7

8

9

HILARY FORD, ${ }^{1,4}$ BEN EVANS, ${ }^{2}$ ROEL VAN KLINK, ${ }^{3}$ MARTIN W. SKOV, ${ }^{1}$ and ANGUS GARBUTT ${ }^{4}$

${ }^{1}$ School of Ocean Sciences, Bangor University, Anglesey, LL59 5AB, UK, ${ }^{2}$ Cambridge Coastal Research Unit, Department of Geography, University of Cambridge, Downing Place, Cambridge CB2 3EN, UK, 3 Institute of Botany, Czech Academy of Sciences, Dukelská 135, 37982, Třeboň, Czech Republic, ${ }^{4}$ Centre for Ecology and Hydrology, Environment Centre Wales, Bangor, LL57 2UW, UK.

Correspondence: Hilary Ford, School of Environment, Natural Resources and Geography, Thoday buildings, Bangor University, LL57 2DG, UK. Telephone: +44(0)1248 382443. E-mail: hilary.ford@bangor.ac.uk

\section{Running title: Canopy complexity and invertebrates}

Abstract. 1. Habitat structure, including vegetation structural complexity, largely determines invertebrate assemblages in semi-natural grasslands. The importance of structural complexity to the saltmarsh invertebrate community, where the interplay between vegetation characteristics and tidal inundation is key, is less well known.

2. We hypothesised that canopy complexity would be a more important predictor of spider and beetle assemblages than simple vegetation attributes (e.g. height, community type) and environmental variables (e.g. elevation) alone; measured in two saltmarsh regions, south-east (Essex) and north-west (Morecambe Bay) UK. Canopy complexity (number of non-vegetated 'gaps' in canopy $\geq 1 \mathrm{~mm}$ wide) was assessed using side-on photography. Over 1,500 spiders and beetles were sampled via suction sampling, winter and summer combined. 
3. In summer, saltmarshes with abundant spider and beetle populations were characterised by high scores for canopy complexity often associated with tussocky grass or shrub cover. Simple vegetation attributes (plant cover, height) accounted for $26 \%$ of variation in spider abundance, $14 \%$ in spider diversity; rising to 46 and $41 \%$ respectively with the addition of canopy complexity score. Over-wintering spider assemblages were associated with elevation and vegetation biomass. Summer beetle abundance, in particular the predatory and zoophagous group, and diversity were best explained by elevation and plant species richness.

4. Summer canopy complexity was identified as a positive habitat feature for saltmarsh spider communities (ground-running hunters and sheet weavers) with significant 'added value' over more commonly measured attributes of vegetation structure.

Key words. CBESS, invertebrate, over-wintering, salt marsh, structural complexity, vegetation structure.

\section{Introduction}

Small-scale vegetation structural complexity plays a key part in shaping grassland invertebrate assemblages (Morris, 2000). Habitat complexity is associated with features such as availability of foraging sites, shelter and over-wintering or nesting sites, indicating abundance of resources (prey, pollen or nectar) and suitable refuges from predators, intra-guild cannibalism and competitors (Halaj et al., 2000; McNett \& Rypstra, 2000; Langellotto \& Denno, 2004; Finke \& Denno, 2006). Habitat complexity might also be considered an explanatory factor in species-area relationships (Hart \& Horwitz, 1991). Enhanced structural complexity may offer greater space-size heterogeneity, providing habitable space to organisms with a wide range of body sizes, thereby increasing species richness (Tokeshi \& Arakaki, 2012; Pierre \& 
Kovalenko, 2014). To determine the vegetation characteristics that best describe the relationship between arthropod communities and the vegetation they inhabit, various methods have been used. These include fractal geometry, architectural or branching complexity, soil microhabitat complexity, multi-variable habitat heterogeneity and vegetation density (Anderson, 1978; Hatley \& MacMahon, 1980; Dennis et al., 1998; Halaj et al., 2000; McNett \& Rypstra, 2000; Dennis, et al. 2001; Whitehouse et al., 2002; Woodcock et al., 2007). In contrast, other studies tend to focus on simple measurements, such as vegetation height or above-ground biomass, often in concert with livestock grazing intensity. In this study, we introduce a novel side-on photography technique to accurately record vegetation structural complexity, via the quantification of canopy gaps, at a scale relevant to invertebrate communities.

Certain invertebrate groups, specifically generalist predators and spiders, appear to prefer more complex habitats (McNett \& Rypstra, 2000; Shrewsbury \& Raupp, 2006), with spiders in particular negatively affected when habitat structure is simplified (Marshall \& Rypstra, 1999; Langellotto \& Denno, 2004; Wise, 2006). Ground-dwelling spider communities respond to commonly measured structural attributes such as height, above-ground biomass, vegetation tip height diversity and depth of plant litter layer (Uetz et al., 1999; Bonte et al., 2000; Bell et al., 2001; Traut, 2005; Pétillon et al., 2008), but do not exhibit strong host-plant associations. Both phytophagous and predatory beetle habitat preferences are associated with commonly measured attributes of vegetation structure (Lassau et al., 2005; Hofmann \& Mason, 2006; Woodcock et al., 2007) and satellite-derived vegetation indices (Lafage et al., 2014).

Plant species richness may also contribute to vegetation structural complexity, and affect the abundance and species richness of predatory arthropods such as spiders and predatory 
beetles via bottom-up trophic effects (Scherber et al., 2010). A species-rich plant community tends to support a large number of herbivorous arthropods which in turn boosts the predatory arthropod population (Borer et al., 2012). The 'Enemies Hypothesis' (Root et al., 1973), proposes a mechanism of top-down control in which diverse vegetation assemblages provide more refuges for predatory arthropods and more opportunity for stable prey availability than low plant diversity assemblages, leading to higher predator efficiency and the resultant link between plant species richness and predatory arthropod abundance (Russell, 1989). The habitat heterogeneity hypothesis (Dennis et al., 1998) predicts an asymptotic relationship between increasing plant species richness and vegetation structural heterogeneity, with greater resources available for the coexistence of multiple species of arthropods of each trophic group in structurally complex vegetation.

Ground and canopy dwelling invertebrates are sensitive to seasonal changes in environmental characteristics, such as changes in vegetation structure due to natural die-back in winter, but seasonal invertebrate- vegetation structure relations are rarely quantified. Dense vegetation may be important in winter for different reasons than in the summer. For example, tussocky grasses and leaf litter provide over-wintering shelter from predators for ground-dwelling invertebrates including wolf spiders (Edgar \& Loenen, 1974; Collins et al., 2002; Lewis \& Denno, 2009), whereas in spring and summer, prey availability is often crucial (Wise, 2006) encouraging individuals to explore more open habitat. Tall vegetation offers several benefits for invertebrates including protection from predation and shelter from extreme weather events. However, daytime temperatures are lower in tall vegetation, potentially hindering thermophilic invertebrates, inhibiting movement and hiding prey, especially in dense grass mats such as Festuca rubra (Linnaeus) swards (Van Klink et al., 2014). Hence, vegetation that 
is tall, but not dense may be optimal. This level of vegetation structural detail, e.g. canopy openness, is difficult to capture, and simple measurements of vegetation height or aboveground biomass will not portray intricacies such as canopy gap availability.

Saltmarshes provide an important habitat for invertebrates, plants and insectivorous birds (Milsom et al., 2000; Chatters, 2004; Pétillon et al., 2005). They are characterised by a suite of plant communities differing in structural complexity, ranging from grass to shrub or rush dominated, making saltmarshes an ideal habitat to study the interplay between vegetation structural complexity and invertebrate assemblages. The two invertebrate orders focused on in this study, Araneae and Coleoptera, were chosen as they are well studied, known to respond to habitat complexity and are often used as bio-indicators of ecosystem health (Pearce \& Venier, 2006).

The relationship between ground and canopy dwelling invertebrate communities and plant canopy complexity was examined, via suction sampling, in two English saltmarsh regions, south-east (Essex) and north-west (Morecambe Bay), in summer and winter. We used a novel side-on photography technique to record canopy complexity, via the quantification of canopy gaps. We examined the following two hypotheses: i) Canopy complexity will be a more important predictor of spider and beetle assemblages than simple vegetation attributes (e.g. height, community type) and environmental variables (e.g. surface elevation) alone. As the measurement of canopy complexity allows us to access a level of vegetation structural detail not captured by more commonly measured vegetation characteristics; and ii) Winter canopy complexity will be positively associated with spider abundance due to the provision of shelter and ability to avoid over-wintering wolf spiders, prone to preying on both smaller spiders and to cannibalism. The impact of winter canopy complexity on beetles is largely unknown. 
Three marshes from Essex (south-east England) and three from the greater Morecambe Bay area (north-west England) were selected to represent two distinct saltmarsh regions differing broadly in inundation frequency and dominant vegetation type. In Essex, Abbotts Hall (AH; $\left.51^{\circ} 47^{\prime} \mathrm{N}, 0^{\circ} 52^{\prime} \mathrm{E}\right)$, Fingringhoe Wick (FW; $\left.51^{\circ} 49^{\prime} \mathrm{N}, 0^{\circ} 58^{\prime} \mathrm{E}\right)$ and Tillingham marsh (TM; $51^{\circ}$ $41^{\prime} \mathrm{N}, 0^{\circ} 56^{\prime} \mathrm{E}$ ) were all lagomorph grazed with Abbotts Hall and Fingringhoe Wick both heavily grazed by over-wintering Brent geese (Branta bernicla Linnaeus) (Austin et al., 2014). In Morecambe Bay, Cartmel Sands (CS; $54^{\circ} 10^{\prime} \mathrm{N}, 3^{\circ} 0^{\prime} \mathrm{W}$ ) and Warton Sands (WS; $54^{\circ} 8^{\prime} \mathrm{N}, 2^{\circ}$ $48^{\prime} \mathrm{W}$ ) were intensively sheep grazed $(\sim 4-5$ sheep ha-1) with pink-footed geese (Anser brachyrhynchus Baillon) grazing during the winter. In contrast, West Plain (WP; $54^{\circ} 9^{\prime} \mathrm{N}, 2^{\circ}$ $\left.58^{\prime} \mathrm{W}\right)$, in Morecambe Bay, was lightly grazed $(<2$ sheep ha-1), with historical annual cattle grazing potentially leading to a legacy effect on vegetation structure.

All experimental sites were sampled in winter 2013 (January/February) and again in late summer 2013 (August/September). In each study site we selected an area of 20 to 100 ha in size, dependent upon saltmarsh length (parallel to shore) and width (perpendicular to shore), including part of the low, mid and high marsh zones. Twenty two $1 \times 1 \mathrm{~m}$ quadrats were marked in each site, according to a stratified random pattern.

Above-ground vegetation characteristics were measured from within each $1 \times 1$ m quadrat. Percentage cover of each plant species within each quadrat was estimated by eye. Shannon- 
diversity. British National Vegetation Classification (NVC) plant community types were calculated for each quadrat using Tablefit v1.1 (Hill, 2011). All plant nomenclature follows Stace (2010). Above-ground dry vegetation biomass ( $60^{\circ} \mathrm{C}, 72 \mathrm{~h}$ ) was determined by cutting plants to ground level from a $50 \times 25 \mathrm{~cm}$ area within each quadrat. Vegetation height was recorded at 10 random positions within each quadrat using a direct measurement (hand slid down metre stick until vegetation detected then height in $\mathrm{cm}$ recorded). Mean height per quadrat was used in the analysis. The standard deviation of height within each quadrat was calculated as a potential proxy for combined vegetation structure and height complexity. Coefficient of variation (CoV; Standard Deviation /Mean x 100) in vegetation height (CoV ${ }^{1}$ ) was calculated from the 10 direct vegetation height measurements per quadrat.

Vegetation structure: side-on photography method

Digital photographs to determine vegetation structure were taken side-on within each quadrat through a $20 \mathrm{~cm}$ deep section of vegetation, against a $60 \mathrm{~cm}$ wide red back board (Fig. 1a) at a fixed distance from the camera using a FujiFilm Finepix XP30 digital camera at full 14MP resolution following the method of Möller (2006). Photographs were only taken at quadrat locations where vegetation height exceeded the height of the steel frame $(25 \mathrm{~mm})$, with vegetation clearly visible against the backboard. The Matlab Camera Calibration Toolbox (Bouguet n.d.) was used to correct and calibrate the images, ERdas Imagine software was used for image classification. Unsupervised classification of the 3 band images into 20 classes was followed by manual attribution and recoding of those classes to either 'vegetation' or 'non-vegetation' with visual reference to the original photograph. Variations in illumination, 
meant that fully unsupervised classification did not provide consistent results. Matlab was subsequently used to process thematic images (Fig. 1b; doi reference to be added).

Structural complexity was assessed via a canopy complexity score, calculated as number of non-vegetated 'gaps' in canopy $\geq 1 \mathrm{~mm}$ wide, standardised to number of gaps per metre. This standardisation was important as background images varied slightly in horizontal width but were always close to $60 \mathrm{~cm}$ (width of back board). Henceforth, this 'canopy complexity score' will be referred to as 'canopy complexity'. Mean, median and standard deviation in 'gap' area for each quadrat were also calculated, alongside maximum gap area (combined area of all gaps in one quadrat), but were not found to relate to the structuring of spider and beetle assemblages. They will not be discussed further in this manuscript. Vertical vegetation density (from now on 'vegetation density') was calculated from each quadrat image by the proportion of the image classed as vegetation normalised by the horizontal extent of the image - i.e. $\mathrm{mm}^{2} / \mathrm{mm}$. Vegetation tip height diversity $\left(\mathrm{CoV}^{2}\right)$ was measured by the coefficient of variation. $\mathrm{CoV}^{2}$ was calculated from the highest vegetation point measured from ten random columns of pixels per quadrat photograph.

\section{Physical characteristics}

Saltmarsh elevation and salinity were measured as these can determine the distribution of some saline sensitive saltmarsh invertebrates. Elevation and $x, y$ coordinates of each quadrat were measured by a Leica GS08 GNSS Differential Global Positioning System (DGPS) with CRS

$177=\mathrm{OSGB}(36)$ accuracy of $< \pm 0.05 \mathrm{~m}$. Elevation was recorded in metres relative to Ordnance Datum Newlyn (ODN), converted to Chart Datum (CD) and presented relative to Mean High Water Neap (MHWN) as a rough proxy for tidal inundation frequency. Soil salinity was measured by proxy of electrical conductivity $(E C)$ in the lab. Soil samples, of $\sim 10 \mathrm{~g}$ (fresh mass) 
from the top $10 \mathrm{~cm}$, were taken from within each quadrat, diluted by 1:2.5 with deionised water and measured for $\mathrm{EC}\left(\mathrm{mS} \mathrm{cm}^{-1}\right)$ and $\mathrm{pH}$ using a Jenway 4320 conductivity meter. Soil bulk density was calculated from bulk density ring $(3.1 \mathrm{~cm}$ height, $7.5 \mathrm{~cm}$ diameter) samples taken vertically to roughly quantify the $0-10 \mathrm{~cm}$ depth zone. Samples were dried $\left(105^{\circ} \mathrm{C}, 72\right.$ h) prior to calculation of bulk density. Soil moisture content was also calculated.

Araneae and Coleoptera - Suction sampling

Ground and vegetation dwelling invertebrates were suction sampled from each $1 \times 1 \mathrm{~m}$ quadrat using a modified garden vacuum (McCulloch MAC GBV345 Petrol Leaf Blower Vac $25 \mathrm{cc}$ ). Each sample consisted of four 20 second suctions at four regularly placed intervals within the quadrat with a $20 \mathrm{~cm}$ diameter circular tube containing a 500 micron mesh to trap invertebrates. Care was taken to place the sampler tube end over the top of vegetation where possible, whilst maintaining good contact with the ground surface to ensure efficiency of sampling. In Atriplex portulacoides (Aellen) bushes we squashed the vegetation down with the sampler end to enable sampling through the column of vegetation and the soil surface. Where vegetation was very long, for example in Juncus maritimus (Lam) swards of up to 70 $\mathrm{cm}$ high we were not able to do this and so focused on bottom $10 \mathrm{~cm}$ of vegetation and soil surface. Each sample was then preserved in $70 \%$ industrial methylated spirits. Araneae and Coleoptera were identified to lowest possible taxonomic level, which in most cases was species, but in some cases genus or subfamily with a Novex stereoscope. Early stage juveniles, predominantly Linyphiidae, were classified to family level for Araneae. The majority of later stage juvenile Pardosa were assumed to be the most common saltmarsh species Pardosa purbeckensis (Cambridge). Invertebrate nomenclature follows Duff (2012) for Coleoptera and the World Spider Catalog (2016) for Araneae. Spider feeding guilds of ground running hunters, 
foliage running hunters, sit and wait hunters, sheet weavers, space web builders and orb web weavers were classified according to Uetz et al. (1999). Beetles were grouped into predatory, zoophagous (predatory and scavenging), phytophagous (herbivore or granivorous) or detritivore (feed on detritus and associated decomposer community of fungi and bacteria) using several sources listed in the footnotes to Table S4. Spider or beetle species confined to saline habitats were classified as 'coastal specialists' whereas species occurring in habitats other than saltmarshes (usually other wet habitats or sand dunes) were classified as 'noncoastal specialists' (Hänggi et al., 1995; Van Klink, 2014).

\section{Statistical analysis}

Relationships between environmental variables and the abundance and species richness of the different invertebrate groups were examined using a generalized linear model with a nested structure (random $=\sim 1$ region/site/quadrat) and a Poisson distribution suitable for invertebrate count data, tested for over-dispersion (if ratio between residuals ${ }^{2}$ and residual degrees of freedom is $>5$ data is over-dispersed). Best fit models were selected on the basis of lowest Akaike information criterion (AIC) value for three analyses: 1 . Standard environmental variables (Elevation above MHWN + Plant cover + Plant species richness + Height + Above-ground biomass); 2. Standard environmental variables plus canopy complexity score; 3 . Standard environmental variables plus side-on photography variables (Density + Vegetation tip height diversity + canopy complexity score) allowing the 'value added' component of the side-on photography method to be assessed. Analysis was carried out on the following spider feeding guilds: ground running hunters; foliage running hunters; and sheet weavers. Space web builders, orb web weavers and sit and wait hunters were excluded due to very low abundance. Beetles were analysed in two broad groups: i) predatory 
and zoophagous and ii) phytophagous and detritivores. Generalised linear models (as detailed above) were also used to analyse regional differences in invertebrate abundance.

Testing for significant differences in vegetation and physical characteristics between regions

230 (Essex, Morecambe bay) and site (AH, FW, TM, CS, WP, WS) was carried out using ANOVA output of a linear model, variables were logged where appropriate to normalise data, and post hoc Tukey tests calculated (Hothorn et al., 2008). The relationship between elevation above MHWN and EC (proxy for salinity) was determined by Spearman's rank correlation coefficient.

Nonmetric Multidimensional scaling (NMDS) was used to assess how environmental factors, vegetation structure and site characteristics, influenced individual spider and beetle species habitat preferences. NMDS, an un-constrained ordination technique using rank order of species abundances, was carried out with Bray-Curtis dissimilarity calculations (1000 permutations) using the 'vegan' package (Oksanen et al., 2016). To be included within either the winter or summer NMDS analysis each spider or beetle species had to have $\geq 10$ individuals in total across all quadrats, Essex and Morecambe Bay saltmarsh sites combined.

242 For pairs or sets of closely related environmental variables (e.g. vegetation height, aboveground biomass) only one variable was retained in the analysis based on an $r_{s}$ value of $\geq 0.5$

244 (Spearman's rank correlation coefficient). All statistical analysis was carried out in R (R Core 245 Team, 2015). 
Vegetation height and above-ground biomass were greater for Essex than Morecambe Bay saltmarshes in both summer and winter (Tables S1 \& S2). Summer plant diversity (S-W index) was greater in Morecambe Bay than Essex. For plant community (NVC) type the Essex marshes, Abbots Hall and Fingringhoe Wick were dominated by Puccinellia maritima (Hudson) community (SM13), a common saltmarsh grass species. Tillingham, in contrast, was characterised by $A$. portulacoides community (SM14), a common open saltmarsh shrub. For Morecambe Bay, Cartmel sands was dominated by a short sward of $P$. maritima (SM13), West

Plain and Warton sands by Juncus gerardii (Loisel, SM16) and J. maritimus (SM18) communities. J. maritimus communities are characterised by large tussocks of J. maritimus, a large rush up to $70 \mathrm{~cm}$ tall.

Vegetation structure: side-on photography method

Canopy complexity was variable across sites, with Tillingham and West plain gaining the highest summer scores for Essex and Morecambe Bay respectively (Table S1 \& S2). For information on vegetation diversity and vegetation tip height diversity see Tables S1 \& S2.

Physical characteristics

Elevation relative to $\mathrm{MHWN}$ was significantly greater for Morecambe Bay ( $2.5 \mathrm{~m}$ ) than Essex saltmarshes were tidally inundated more often (despite differences in tidal range). This was confirmed by soil EC, a proxy for salinity, and soil moisture content being appreciably greater

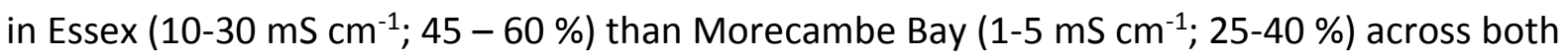


winter and summer. Elevation relative to MHWN was significantly negatively associated with EC in both summer (SPEARMANS: $\left.r_{s}=-0.77, p<0.001\right)$ and winter $\left(r_{s}=-0.82, p<0.001\right)$. Elevation was also a stronger predictor of spider and beetle assemblages than EC in all statistical models. For these reasons elevation relative to MHWN was used instead of EC in the final set of models presented in this study. For site means and further information see Tables S1 \& S2.

\section{Regional differences: Araneae and Coleoptera}

Nearly 400 spiders were sampled in winter, $60 \%$ from Essex. Over 1000 were sampled in the summer with $72 \%$ from Essex, Tillingham supported the most with $>400$ individuals (Table S3). Summer spider abundance and species richness were significantly greater in Essex than Morecambe Bay (Table S5, S6). However, total Araneae species richness, across sites and seasons, between Essex and Morecambe Bay was equal with 23 species apiece. Only 24 beetles were found in winter across all six sites, $75 \%$ from Morecambe Bay. Nearly 300 were sampled in summer with $58 \%$ from Morecambe (Table S4). Summer Coleoptera abundance showed marked differences between saltmarsh sites with shrubby Tillingham and tussocky West Plain having particularly abundant populations (Table S4), but with no significant difference between the two regions (Table S5). Total Coleoptera species richness, across sites and seasons, was greater for Morecambe Bay (26) than Essex (21).

\section{Summer: Araneae}

Summer spider abundance was associated positively with plant cover, canopy complexity and plant density, negatively with elevation above MHWN (Table 1). The best fit model for spider abundance improved from $26 \%$ of variation explained for standard environmental variables 

alone to $46 \%$ with the addition of canopy complexity. Ground running hunters were positively associated with plant cover, height and canopy complexity, negatively with elevation (Table 1). Foliage running hunters were aligned with elevation and either vegetation height or density (depending on model type). Sheet weavers (including juveniles) were significantly associated with canopy complexity (Table 1). When spiders were analysed by feeding guild the importance of canopy complexity in explaining variation in abundance was much reduced (0.01 or $1 \%$ increase in $r^{2}$ compared to standard variables alone) compared to when spiders were considered as a group ( 0.2 or $20 \%$ increase in $r^{2}$ ).

The summer NMDS analysis included 7 spider species, with five environmental variables associated with invertebrate habitat choice (Fig. 2), canopy complexity $(p<0.001)$, vegetation height $(p<0.001)$, plant cover $(p<0.001)$, plant species richness $(p<0.01)$ and elevation richness appear closely correlated on the summer NDMS plot they are only partially correlated with an $r_{s}$ value of 0.43

Spider species richness was positively associated with plant cover, plant height and canopy complexity, and negatively associated with elevation above MHWN. The best fit model for spider species richness improved from $14 \%$ of variation explained for standard environmental variables alone to $41 \%$ with the addition of canopy complexity. Interestingly, spider abundance in Essex, including juveniles, was well predicted by shrubby A. portulacoides cover alone $(t=2.50, p<0.05)$ although this relationship does not hold for spider diversity or when juveniles are removed. There was a significant positive relationship between canopy complexity and $A$. portulacoides cover (SPEARMANS: $r_{\mathrm{s}}=0.6, \mathrm{p}<0.001$ ) in Essex. 
Models using environmental predictors of spider assemblages in winter performed much poorer than summer models with typically only $2-19 \%$ of variation in abundance explained (Table 2). For all spiders combined and ground-running hunters abundance was negatively associated with elevation above MHWN. For sheet weavers this relationship was reversed, with a positive link between abundance and elevation (Table 2). Winter NMDS analysis of 4 over-wintering spider species indicated that elevation above MHWN $(p<0.001)$ and vegetation biomass $(p<0.01)$ both significantly influenced species habitat choice (Fig. 2$)$.

Beetle abundance and species richness were positively linked to plant cover and elevation above MHWN, with beetle abundance negatively associated with plant species richness (Table 1). The predatory and zoophagous beetle group responded in a similar way to beetles as a whole but the phytophagous and detritivore group showed no significant response to either elevation or any structural variables. Neither beetle abundance, or species richness, were significantly associated with canopy complexity. Beetle abundance in Essex, including juveniles, was positively correlated to $A$. portulacoides cover $(t=218, p<0.05)$, but not explicitly to canopy complexity. The summer NMDS analysis was dominated by 7 common spider species but did include 3 beetle species (Fig. 2). Additional results can be seen in the Supporting Information (Tables S1-S6).

Winter: Coleoptera individuals sampled. 
The abundance of coastal specialist species, spiders and beetles combined (as defined in:

Table S3 \& S4), was greater in the more saline Essex marshes in summer (ANOVA; $F=65.27$, d.f. $=1, p<0.001)$. Abundance of coastal specialists was correlated negatively with elevation above MHWN (Table $1 ; 2$ ) in both summer and winter.

\section{Discussion}

Vegetation structural complexity is recognised as a key component determining the invertebrate communities of semi-natural grasslands (Morris, 2000). Here we showed that saltmarsh vegetation characterised by high complexity, regardless of region, exhibited the greatest abundance and species diversity of spiders and beetles. For Araneae specifically, canopy complexity explained close to twice as much of the variation in spider abundance and diversity than standard vegetation measurements (plant cover, height) and elevation combined. However, when spiders were grouped by feeding guild the importance of canopy complexity in explaining variation in abundance was much reduced. Environmental and standard vegetation characteristics were better at predicting predatory and zoophagous beetle abundance and diversity than canopy complexity per se. For over-wintering spiders surface elevation and above-ground plant biomass were more important indicators of abundance than canopy complexity.

Spider and beetle assemblages

Spiders responded positively to canopy complexity, with ground-running hunting spiders in particular more abundant in complex, tall vegetation, as in other grassland studies (McNett 
did not respond as clearly or positively to canopy complexity as spiders, mirroring the mixed responses to vegetation height seen in the literature (Morris, 2000; Woodcock et al., 2007; Ford et al., 2013). Despite the different responses of Coleoptera and Araneae to canopy complexity, both were abundant in the 'gappy' shrub cover of $A$. portulacoides. This vegetation type is often characterised by an even shrub layer, $\sim 25 \mathrm{~cm}$ in height, with many small gaps, $\geq 1 \mathrm{~mm}$, present throughout the whole canopy layer, unlike grass swards which often have very few non-vegetated canopy gaps at ground level. We propose that the complex canopy of an A. portulacoides dominated plant community allows shelter from inundation, storms and predators coupled with freedom of movement, providing ideal living conditions for many ground-dwelling invertebrates (Langellotto \& Denno, 2004; Finke \& Denno 2006). Despite the strong link apparent between habitat complexity and overall abundance and diversity, certain groups preferred less complex habitats. For example, Linyphiidae, especially specialist thermophiles such as Erigone and Oedothorax species, were commonly found in shorter, less complex vegetation. Erigone longipalpis (Sundevall), a coastal specialist, was associated with more saline environments than Oedothorax fuscus (Blackwall), an open ground grassland generalist. It is likely that $O$. fuscus, an active aeronaut, disperses into open habitats, such as close-cropped saltmarsh, where competition from larger invertebrate predators is low (Gibson et al., 1992; Bell et al., 2001; Ford et al., 2013).

Beetle species richness was positively associated with plant cover and surface elevation as in other saltmarshes (Irmler et al., 2002; Finch et al., 2007). Coleoptera lack submersion resistance techniques (Rothenbücher \& Schaefer, 2006), possibly explaining why they were more abundant in drier Morecambe Bay than wetter, more frequently inundated, Essex. Surprisingly, a strong negative link was apparent between beetle abundance and plant species 
richness. This has been found in grassland studies (Koricheva et al., 2000) and in shrubby forest (Zou et al., 2013), but stands in contrast to the more commonly postulated Enemy Hypothesis which predicts a positive relationship between plant species richness and predatory arthropod diversity. It is possible that increased plant diversity and the assumed associated increase in phytophagous prey may lead to enhanced competition between predatory Coleoptera and other predatory arthropods, such as spiders, leading to an eventual reduction in beetle abundance, as suggested by Zou et al. (2013).

Spiders were much more likely to over-winter on the saltmarsh than beetles with three species P. purbeckensis, Pachygnatha degeeri (Sundevall) and O. fuscus proving the most abundant. The strong link observed between above-ground vegetation biomass and the overwintering wolf spider, $P$. purbeckensis was also demonstrated in juveniles by Kessler $\&$ Slings (1980), possibly due to protection from predators, avoidance of cannibalism and warmth (Wise, 2006; Lewis \& Denno, 2009). In contrast, the small ground running spider, P. degeeri, and the open grassland generalist Linyphiidae, $O$. fuscus, over-wintered in large numbers in the short-cropped Morecambe Bay saltmarshes. Linyphiidae juveniles over-wintered in all study saltmarshes, regardless of vegetation height or structure. the relationship between vegetation structure and invertebrate assemblage patterns, specifically via measurements of vegetation tip height diversity, vegetation density and canopy complexity. Vegetation tip height diversity was not a significant explanatory variable. However, vegetation density and canopy complexity both 'added value' to best fit models of spider abundance, with twice as much variation in abundance explained as standard 
environmental and vegetation measurements alone. Canopy complexity is of particular interest as a measurement of vegetation structural complexity. Previously, grassland canopy complexity has been assessed by vertical drop pins (Woodcock, et al., 2007), with number of contacts between vegetation and pins used to calculate a complexity index. Our method is roughly analogous to this with canopy complexity calculated from number of canopy gaps $\geq$ $1 \mathrm{~mm}$ wide, but is likely to be less time consuming. Canopy complexity also seems to be partially responsible for the positive relationship seen between spider and beetle abundance and cover of the 'gappy' saltmarsh shrub A. portulacoides. The side-on photography method may be advantageous over standard vegetation measurements that may be either destructive (e.g. above-ground biomass) or prone to human error (e.g. direct measurement of vegetation height). We argue that the assessment of vegetation structure by side-on photography proves a useful and novel addition to standard vegetation methods. However, one issue limits it effectiveness in shorter swards with vegetation $\leq 25 \mathrm{~mm}$ high not appearing in images due to height of base, reducing its usefulness for assessing small scale structural complexity.

\section{Acknowledgements}

This study presents data collected as part of the Coastal Biodiversity and Ecosystem Service Sustainability project (CBESS: NE/J015644/1), part of the BESS programme; a six-year programme (2011-2017) funded by the Natural Environment Research Council (Bangor University grant reference: NE/J015350/1) and the Biotechnology and Biological Sciences Research Council (BBSRC) as part of the UK's Living with Environmental Change (LWEC) programme. The views expressed are those of the authors and do not reflect the views of BESS Directorate or NERC. A.G. and M.W.S. acknowledge financial support from the Welsh Government and Higher Education Funding Council for Wales through the Sêr Cymru National 
Research Network for Low Carbon, Energy and Environment. Thanks also to Rachel Kingham,

Cai Ladd and Simon Mehrtens for fieldwork assistance.

\section{Supporting information}

Additional Supporting Information may be found in the online version of this article under the DOI reference: $x x x x x x x$

Table S1. Site characteristics for east and west coast English saltmarshes, winter 2013. Means per site are shown \pm standard deviation. Italicised letters denote significant site differences, final column, regional differences between Essex $(\mathrm{AH}=$ Abbotts Hall, $\mathrm{FW}=$ Fingringhoe Wick, $\mathrm{TM}=$ Tillingham marsh $)$ and Morecambe Bay $(\mathrm{CS}=$ Cartmel sands, WP $=$ West Plain, WS = Warton sands).

Table S2. Site characteristics for east and west coast English saltmarshes, summer 2013. Means per site are shown \pm standard deviation. Italicised letters denote significant site differences, final column regional differences between Essex $(\mathrm{AH}=\mathrm{Abbotts}$ Hall, FW $=$ Fingringhoe Wick, TM = Tillingham marsh) and Morecambe Bay (CS = Cartmel sands, WP = West Plain, WS = Warton sands).

Table S3. Total counts of all Araneae sampled in winter and summer 2013 from Essex (AH = Abbotts Hall, FW = Fingringhoe Wick, $\mathrm{TM}=$ Tillingham marsh) and Morecambe Bay (CS = Cartmel sands, WP $=$ West Plain, WS $=$ Warton sands) saltmarsh study sites. 'Group' column indicates prey capture method as all spiders are predatory; GRH = Ground running hunter, $\mathrm{FRH}=$ Foliage running hunter, SWB $=$ Space web builder, ORB = Orb web weaver, SIT = Sitand-wait, SW = Sheet weaver (Uetz et al. 1999). CS = Coastal specialist as defined by Van Klink (2014) and Hänggi et al. (1995), nomenclature follows World Spider Catalog (2016). 
447 Table S4. Total counts of all Coleoptera sampled in winter and summer 2013 from Essex (AH $448=$ Abbotts Hall, FW = Fingringhoe Wick, $\mathrm{TM}=$ Tillingham marsh) and Morecambe Bay (CS $=$ 449 Cartmel sands, WP $=$ West Plain, WS $=$ Warton sands) saltmarsh study sites. 'Group' column 450 indicates functional group assignment; $\mathrm{PRE}=$ predatory, $\mathrm{ZOO}=$ Zoophagous, $\mathrm{PHY}=$ 451 Phytophagous, DET = Detritivore. CS = Coastal specialist defined by Van Klink (2014), 452 nomenclature follows Duff (2012).

453 Table S5. Summer comparison of invertebrate abundance and species richness. Quadrat 454 means per region are shown \pm standard error.

455 Table S6. Winter comparison of invertebrate abundance and species richness. Quadrat means 456 per region are shown \pm standard error. 
Anderson, J.M. (1978) A method to quantify soil-microhabitat complexity and its application to a study of soil animal species diversity. Soil Biology and Biochemistry, 10, 77-78. management for the conservation of spider communities: a review. Journal of Zoology, 255, 377-387.

463 Bonte, D., Maelfait, J.-P., \& Hoffman, M. (2000) The impact of grazing on spider communities in a mesophytic calcareous dune grassland. Journal of Coastal Conservation, 6, 135-144. biomass and temporal stability. Ecology letters, 15, 1457-1464.

Bouguet, J.-Y. (n.d.) Camera Calibration Toolbox for Matlab. [WWW document]. URL 468 http://www.vision.caltech.edu/bouguetj/calib_doc/ [accessed on 16.03.16]. 400.

471 Collins, K.L., Boatman, N.D., Wilcox, A., Holland, J.M. \& Chaney, K. (2002) Influence of beetle banks on cereal aphid predation in winter wheat. Agriculture, Ecosystems and Environment 93, 337-350.

Dennis, P., Young, M.R. \& Gordon, I.J. (1998) Distribution and abundance of small insects and arachnids in relation to structural heterogeneity of grazed, indigenous grasslands. Ecological 
477 Dennis, P., Young, M.R. \& Bentley, C. (2001) The effects of varied grazing management on 478 epigeal spiders, harvestmen and pseudoscorpions of Nardus stricta grassland in upland 479 Scotland. Agriculture, Ecosystems \& Environment, 86, 39-57.

480 Duff, A.G. (2012) Checklist of beetles of the British Isles. [WWW document]. URL 481 http://www.coleopterist.org.uk/checklist2012.pdf [accessed on 6th April 2016].

482 Edgar, W. \& Loenen, M. (1974) Aspects of the overwintering habitat of the wolf spider 483 Pardosa lugubris. Journal of Zoology, 172, 383-388.

484 Finch, O.-D., Krumen, H., Plaisier, F. \& Schultz, W. (2007) Zonation of spiders (Araneae) and 485 carabid beetles (Coleoptera: Carabidae) in island saltmarshes at the North Sea coast. Wetlands Ecology and Management, 15, 207-228.

Finke, D.L. \& Denno, R.F. (2006) Spatial refuge from intraguild predation: implications for prey 488 suppression and trophic cascades. Oecologia, 149, 265-275.

Ford, H., Garbutt, A., Jones, L. \& Jones, D.L. (2013) Grazing management in saltmarsh ecosystems drives invertebrate diversity, abundance and functional group structure. Insect Conservation and Diversity, 6, 189-200. in relation to succession and grazing management. Journal of Applied Ecology 29, 132-142.

Halaj, J., Ross, D.W. \& Moldenke, A.R. (2000) Importance of habitat structure to the arthropod food-web in Douglas-fir canopies. Oikos, 90, 139-152. 
Hart D.D. \& Horwitz R.J. (1991) Habitat diversity and the species-area relationship: alternative models and tests. Habitat Structure: the Physical Arrangement of Objects in Space (ed. by S.S. Bell, E.D. McCoy \& H.R. Mushinsky), pp. 47-68. Chapman \& Hall, London.

Hatley, C.L. \& MacMahon, J.A. (1980) Spider community organization: seasonal variation and the role of vegetation architecture. Environmental Entomology, 9, 632-639.

Hill, M. (2011) Tablefit: A program to identify types of vegetation by measuring goodness-offit to association tables. Version 1.1. URL http://www.ceh.ac.uk/services/tablefit-andtablcorn [accessed on 6th April 2016].

Hofmann, T.A. \& Mason, C.F. (2006) Importance of management on the distribution and abundance of Staphylinidae (Insecta: Coleoptera) on coastal grazing marshes. Agriculture, Ecosystems and Environment, 114, 397-406.

Hothorn, T., Bretz, F. \& Westfall, P. (2008) Simultaneous Inference in General Parametric Models. Biometrical Journal, 50, 346-363.

Irmler, U., Heller, K., Meyer, H. \& Reinke, H.-D. (2002) Zonation of ground beetles (Coleoptera: Carabidae) and spiders (Araneidae) in salt marshes at the North and the Baltic Sea and the impact of the predicted sea level increase. Biodiversity and Conservation, 11, 1129-1147.

Kessler, A. \& Slings, R. (1980) Microhabitat selection in adults and juveniles of Pardosa purbeckensis F.O.P.-Cambridge (Araneae, Lycosidae). Proceedings of the 8th International Congress of Arachnology (ed. by J. Gruber), pp. 151-154, Verlag H. Egermann, Wien. 

responses of different trophic groups of invertebrates to manipulations of plant diversity in grasslands. Oecologia, 125, 271-282.

Lafage, D., Secondi, J., Georges, A., Bouzillé, J.-B. \& Pétillon, J. (2014) Satellite-derived vegetation indices as surrogate of species richness and abundance of ground beetles in temperate floodplains. Insect Conservation and Diversity, 7, 327-333.

Langellotto, G.A. \& Denno, R.F. (2004) Responses of invertebrate natural enemies to complexstructured habitats: a meta-analytical synthesis. Oecologia, 139, 1-10. forest beetle diversity: do functional groups respond consistently? Diversity and Distributions, $11,73-82$.

Lewis, D. \& Denno, R.F. (2009) A seasonal shift in habitat suitability enhances an annual predator subsidy. Journal of Animal Ecology, 78, 752-760.

Marshall, S.D. \& Rypstra, A.L. (1999) Spider competition in structurally simple ecosystems. Journal of Arachnology, 27, 343-350.

McNett, B.J. \& Rypstra, A.L. (2000) Habitat selection in a large orb-weaving spider: vegetational complexity determines site selection and distribution. Ecological Entomology, 25, 423-432. marshes. Journal of Applied Ecology, 37, 706-727. 
Möller, I. (2006) Quantifying saltmarsh vegetation and its effect on wave height dissipation: Results from a UK East coast saltmarsh. Estuarine, Coastal and Shelf Science, 69, 337-351.

Morris, M.G. (2000) The effects of structure and its dynamics on the ecology and conservation of arthropods in British grasslands. Biological Conservation, 95, 129-142.

Oksanen, J., Blanchet, F.G., Kindt, R., Legendre, P., Minchin, R.P., O'Hara, R.B., Simpson, G.L., Solymos, P., Stevens, M.H.M. \& Wagner, H. (2016) Community Ecology Package Version 2.34. [WWW document]. URL https://cran.r-project.org/web/packages/vegan/vegan.pdf 545 [accessed on 6th April 2016].

Pearce, J.L. \& Venier, L.A. (2006) The use of ground beetles (Coleoptera: Carabidae) and spiders (Araneae) as bioindicators of sustainable forest management: a review. Ecological Indicators, 6, 780-793.

Pétillon, J., Ysnel, F., Canard, A. \& Lefeuvre, J.-C. (2005) Impact of an invasive plant (Elymus athericus) on the conservation value of tidal salt marshes in western France and implications for management: responses of spider populations. Biological Conservation, 126, 103-117. abiotic factors on spider and ground beetle communities in different salt-marsh systems. Basic and Applied Ecology, 9, 743-751.

Pétillon, J., George, A., Canard, A. \& Ysnel, F. (2007) Impact of cutting and sheep grazing on

557 Biodiversity and Conservation, 30, 201-209. 
Pierre, J.I. \& Kovalenko, K.E. (2014) Effect of habitat complexity attributes on species richness. Ecosphere, 5(2), 22. http://dx.doi.org/10.1890/ES13-00323.1

R Core Team (2015) R: A language and environment for statistical computing. R Foundation for Statistical Computing, Vienna, Austria. URL http://www.R-project.org/

Root, R.B. (1973) Organization of a plant-arthropod association in simple and diverse habitats: the fauna of collards (Brassica oleracea). Ecological Monographs, 43, 95-124. communities. Basic and Applied Ecology, 7, 398-408.

Russell, E.P. (1989) Enemies hypothesis: a review of the effect of vegetational diversity on predatory insects and parasitoids. Environmental Entomology, 18, 590-599. effects of plant diversity on multitrophic interactions in a biodiversity experiment. Nature, 468, 553-556.

Shrewsbury, P.M. \& Raupp, M.J. (2006) Do top-down or bottom-up forces determine Stephanitis pyrioides abundance in urban landscapes? Ecological applications, 16, 262-272.

Stace, C. (2010) New Flora of the British Isles, third edition. Cambridge University Press, 574 Cambridge, UK.

575 Tokeshi, M. \& Arakaki, S. (2012) Habitat complexity in aquatic systems: fractals and beyond. Hydrobiologia, 685, 27-47.

577 Traut, B.H. (2005) The role of coastal ecotones: a case study of the salt marsh / upland transition zone in California. Journal of Ecology, 93, 279-290. 
579 Uetz, G.W., Halaj, J. \& Cady, A.B. (1999) Guild structure of spiders in major crops. Journal of 580 Arachnology, 27, 270-280.

581 Van Klink, R. (2014) Of Dwarves and Giants: How large herbivores shape arthropod 582 communities on salt marshes. University of Groningen PhD thesis. ISBN: 978-90-367-7083-5

Van Klink, R., Van der Plas, F., Van Noordwijk, C.G.E., WallisDeVries, M.F. \& Olff, H. (2014)

584 Effects of large herbivores on grassland arthropod diversity. Biological reviews, 585 doi:10.1111/brv.12113

Van Klink, R. \& Van Schrojenstein Lantman, M. (2015) Effecten van kwelderbeweiding op spinnen en insecten. Entomologische berichten, 75, 188-199.

Wise, D.H. (2006) Cannibalism, Food limitation, Intraspecific Competition, and the Regulation of Spider Populations. Annual Review Entomology, 51, 441-465.

Whitehouse, M.E.A., Shochat, E., Shachak, M. \& Lubin, Y. (2002) The influence of scale and patchiness on spider diversity in a semi-arid environment. Ecography, 25, 395-404. V.K. (2007) The importance of sward architectural complexity in structuring predatory and phytophagous invertebrate assemblages. Ecological Entomology, 32, 302-311.

World Spider Catalog (2016) World Spider Catalog. Natural History Museum Bern. URL http://wsc.nmbe.ch, version 17.0 [accessed on $17^{\text {th }}$ March 2016]. the abundance and $\alpha$-diversity of predatory ground beetles (Coleoptera: Carabidae) in a mature Asian temperate forest ecosystem. PLOSone, 8, e8279. 
Table 1. Relationship between saltmarsh spider and beetle assemblages and environmental variables in summer, best model fit for standard and side-on photography variables using generalized linear models.

\begin{tabular}{|c|c|c|c|c|c|c|c|c|c|}
\hline & Best fit models: & Elevation & Plant cover & Plant sp. & Height & Canopy complexity & Density & AIC & $R^{2}$ \\
\hline \multicolumn{10}{|l|}{ Spiders } \\
\hline \multirow[t]{3}{*}{ All (including juveniles) } & Standard & ns & $\mathrm{z}=4.45 * * *$ & ns & ns & - & - & 749.1 & 0.26 \\
\hline & Standard + complexity & $\mathrm{z}=-6.36 * * *$ & $\mathrm{z}=3.73 * * *$ & ns & ns & $\mathrm{z}=5.62 * * *$ & - & 710.4 & 0.46 \\
\hline & Standard + photo & $\mathrm{z}=-6.10 * * *$ & $z=3.26 * *$ & $n s$ & ns & $z=4.59 * * *$ & $\mathrm{z}=2.60 * *$ & 705.8 & 0.48 \\
\hline \multirow[t]{3}{*}{ All (excluding juveniles) } & Standard & $\mathrm{z}=-3.41 * * *$ & $\mathrm{z}=14.9 * * *$ & $n s$ & $\mathrm{z}=16.1 * * *$ & - & - & 615.1 & 0.48 \\
\hline & Standard + complexity & $\mathrm{z}=-8.20 * * *$ & $z=3.44 * * *$ & ns & ns & $\mathrm{z}=4.60 * * *$ & - & 600.7 & 0.50 \\
\hline & Standard + photo & $\mathrm{z}=-8.37 * * *$ & $z=2.87^{* *}$ & $n s$ & ns & $\mathrm{z}=3.31 * * *$ & $\mathrm{z}=4.22 * * *$ & 586.0 & 0.57 \\
\hline \multirow[t]{3}{*}{ GRH (including juveniles) } & Standard & $\mathrm{z}=-5.70 * * *$ & $z=3.29 * * *$ & ns & $\mathrm{z}=2.72 * *$ & - & - & 489.4 & 0.52 \\
\hline & Standard + complexity & $\mathrm{z}=-6.74 * * *$ & $z=2.67 * *$ & $n s$ & $z=2.72 * *$ & $z=2.71 * *$ & - & 474.1 & 0.53 \\
\hline & Standard + photo & $\mathrm{z}=-7.71 * * *$ & $\mathrm{z}=2.89 * *$ & $n s$ & ns & $z=2.86 * *$ & $\mathrm{z}=3.01 * *$ & 472.5 & 0.54 \\
\hline \multirow[t]{2}{*}{ GRH (excluding juveniles) } & Standard & $\mathrm{z}=-3.86 * * *$ & $z=2.47^{*}$ & ns & $z=2.45 *$ & - & - & 448.5 & 0.43 \\
\hline & Standard + complexity & $\mathrm{z}=-6.18 * * *$ & ns & ns & $\mathrm{z}=2.72 * *$ & $\mathrm{z}=3.29 * *$ & $-(n s)$ & 435.3 & 0.48 \\
\hline \multirow[t]{2}{*}{$\mathrm{FRH}$} & Standard & $z=2.62 * *$ & ns & $n s$ & $z=2.05 *$ & - & - & 127.6 & 0.06 \\
\hline & Standard + photo & $\mathrm{z}=2.88 * *$ & ns & $n s$ & ns & $-(n s)$ & $z=2.43 *$ & 126.1 & 0.07 \\
\hline \multirow[t]{3}{*}{ SW (including juveniles) } & Standard & ns & $\mathrm{z}=2.86 * *$ & $n s$ & ns & - & - & 654.4 & 0.10 \\
\hline & Standard + complexity & ns & ns & ns & ns & $\mathrm{z}=3.54 * * *$ & - & 628.6 & 0.11 \\
\hline & Standard + photo & ns & ns & ns & ns & $z=2.45 *$ & $z=2.58 * *$ & 623.9 & 0.16 \\
\hline SW (excluding juveniles) & Standard & ns & ns & $n s$ & $z=3.41 * * *$ & $-(n s)$ & $-(n s)$ & 467.6 & 0.09 \\
\hline \multirow[t]{3}{*}{ Species richness } & Standard & ns & $z=2.19 *$ & ns & $z=2.74 * *$ & - & - & 420.4 & 0.14 \\
\hline & Standard + complexity & $\mathrm{z}=-4.54 * * *$ & $z=2.52 *$ & $n s$ & $\mathrm{z}=2.92 * *$ & $\mathrm{z}=2.80 * *$ & - & 399.2 & 0.41 \\
\hline & Standard + photo & $\mathrm{z}=-5.28 * * *$ & $\mathrm{z}=2.76 * *$ & ns & ns & $\mathrm{z}=2.95 * *$ & $z=2.72 * *$ & 400.1 & 0.40 \\
\hline \multicolumn{10}{|l|}{ Beetles } \\
\hline All (including juveniles) & Standard & $z=2.30 *$ & $\mathrm{z}=2.76 * *$ & $z=-3.03 * *$ & $-(n s)$ & $-(n s)$ & $-(n s)$ & 424.2 & 0.26 \\
\hline All (excluding juveniles) & Standard & $z=2.29 *$ & $z=2.02 *$ & $\mathrm{z}=-2.83 * *$ & $-(n s)$ & $-(n s)$ & $-(n s)$ & 404.8 & 0.25 \\
\hline PRE and ZOO & Standard & $z=2.15^{*}$ & ns & $\mathrm{z}=-2.82 * *$ & ns & $-(n s)$ & $-(n s)$ & 247.7 & 0.21 \\
\hline PHY and DET & Standard & ns & ns & ns & $-(n s)$ & $-(n s)$ & $-(n s)$ & - & - \\
\hline Species richness & Standard & $z=2.34 *$ & $z=2.05 *$ & $z=-2.20 *$ & $-(n s)$ & $-(n s)$ & $-(n s)$ & 316.0 & 0.24 \\
\hline \multicolumn{10}{|l|}{ Spiders \& beetles } \\
\hline Coastal specialists & Standard & $\mathrm{z}=-4.93 * * *$ & $z=2.33^{*}$ & ns & $-(n s)$ & $-(n s)$ & $-(n s)$ & 442.5 & 0.46 \\
\hline
\end{tabular}

Best fit models were selected from: 1. Standard environmental variables (Elevation above MHWN + Plant cover + Plant species richness + Height + Aboveground biomass); 2 . Standard environmental variables plus canopy complexity score; 3 . Standard environmental variables plus side-on photography variables 
(Canopy complexity score + Density + Vegetation tip height diversity). Only significant variables are shown: $*=p<0.05, * *=p<0.01, * * *=p<0.001 . R^{2}$ refers to proportion of variation explained by model fixed effects. ' $'$ ' = variable not in model, ' $n s^{\prime}=$ variable not significant $p>0.05$, '- $(n s)$ ' $=$ variable not in listed model and not significant for either' standard + complexity' or 'standard + photo models'. Spider feeding guilds: GRH = Ground running hunter; FRH = Foliage running hunter; SW = Sheet weaver. Beetle diets: $\mathrm{PRE}=$ predatory; $\mathrm{ZOO}=$ zoophagous; $\mathrm{PHY}=$ phytophagous; $\mathrm{DET}=$ detritivore.

Table 2. Relationship between saltmarsh spider and beetle assemblages and environmental variables in winter, best model fit for standard and side-on photography variables using generalized linear models.

\begin{tabular}{|c|c|c|c|c|c|c|c|c|c|}
\hline & Best fit models: & Elevation & Plant cover & Plant sp. & Height & Canopy complexity & Density & $\mathrm{AIC}$ & $\mathrm{R}^{2}$ \\
\hline \multicolumn{10}{|l|}{ Spiders } \\
\hline All (including juveniles) & Standard & $\mathrm{z}=-104.2 * * *$ & ns & ns & ns & $-(n s)$ & $-(n s)$ & 480.1 & 0.02 \\
\hline All (excluding juveniles) & Standard & ns & ns & $n s$ & ns & $-(n s)$ & $-(n s)$ & - & - \\
\hline GRH (including juveniles) & Standard & $\mathrm{z}=-3.51 * * *$ & ns & $n s$ & ns & $-(n s)$ & $-(n s)$ & 292.5 & 0.19 \\
\hline GRH (excluding juveniles) & Standard & ns & ns & $n s$ & ns & $-(n s)$ & $-(n s)$ & - & - \\
\hline SW (including juveniles) & Standard & $n s$ & ns & ns & ns & $-(n s)$ & $-(n s)$ & - & - \\
\hline SW (excluding juveniles) & Standard & $z=2.67 * *$ & ns & $n s$ & $n s$ & - & - & 294.2 & 0.08 \\
\hline Species richness & Standard & ns & ns & $n s$ & $n s$ & $-(n s)$ & $-(n s)$ & - & - \\
\hline Coastal specialists & Standard & $\mathrm{z}=-3.74 * * *$ & ns & ns & ns & $-(n s)$ & $-(n s)$ & 244.4 & 0.26 \\
\hline
\end{tabular}

Best fit models were selected from: 1 . Standard environmental variables (Elevation above MHWN + Plant cover + Plant species richness + Height + Above-

ground biomass); 2 . Standard environmental variables plus canopy complexity score; 3 . Standard environmental variables plus side-on photography variables (Canopy complexity score + Density + Vegetation tip height diversity). Only significant variables are shown: ${ }^{*}=\mathrm{p}<0.05, * *=\mathrm{p}<0.01, * * *=\mathrm{p}<0.001 . \mathrm{R}^{2}$ refers to proportion of variation explained by model fixed effects. '-' = variable not in model, 'ns' = variable not significant $p>0.05$, '- $(n s)$ ' $=$ variable not in listed model and not significant for either' standard + complexity' or 'standard + photo models'. Spider feeding guilds: GRH = Ground running hunter; SW = Sheet weaver. Beetles were excluded from winter analysis due to extremely low numbers of over-wintering individuals sampled. 


\section{Figure list}

Fig. 1. Side-on photography method of determining vegetation structure with a) vegetation photographed in front of a contrasting red back-board and b) representation of canopy gaps identified from image analysis, from which vegetation canopy complexity score was derived.

Fig. 2. NMDS ordination plots for (a) 10 common summer spider and beetle species (b) 4 overwintering spider species across all saltmarsh sites from Essex and Morecambe Bay. Significant environmental predictors $(p<0.01)$ of species abundance are shown alongside arrows. Nonsignificant environmental variables are not shown. Plant_sp $=$ Plant species richess $\mathrm{m}^{2}$, PI_cover = Plant cover (\%), MHWN = Elevation above mean high water neap, Biomass = Above-ground biomass, Canopy_complexity = Canopy complexity score. Invertebrate species names have been shortened to first 4 letters of genus and species (e.g. Pard_purb = Pardosa purbeckensis; full names in Tables S1 \& S2). 


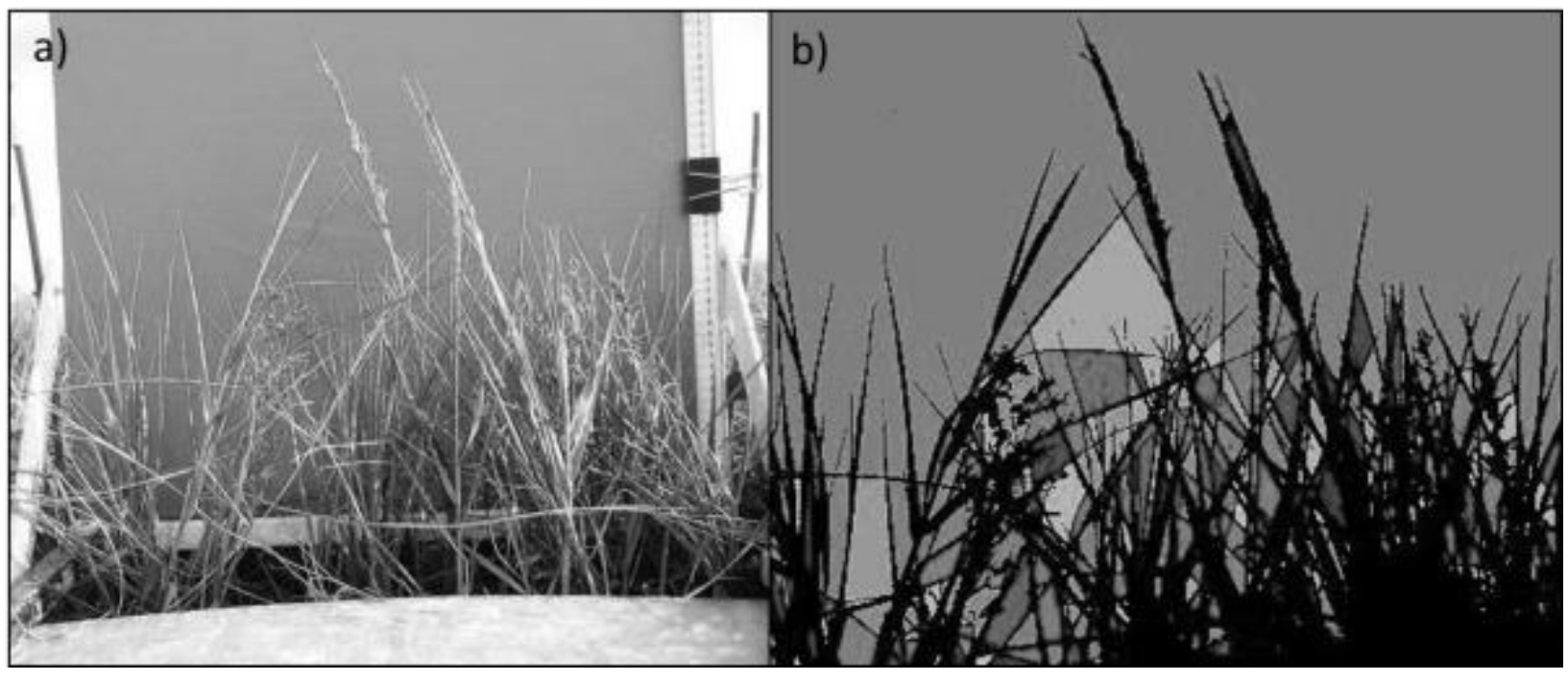

Fig. 1. 

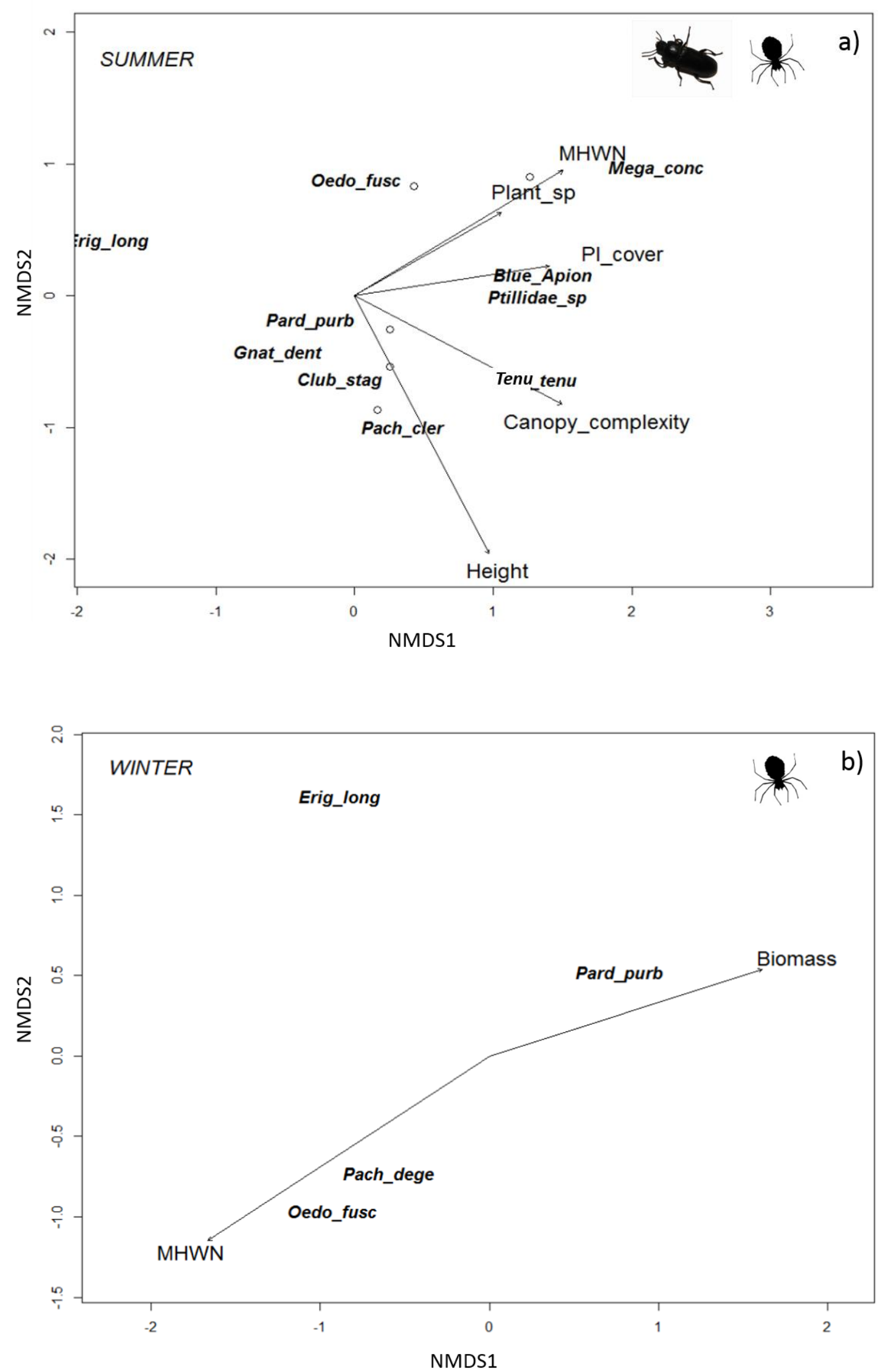

Fig. 2. 